In regard to the willingness of patients to go as "voluntary boarders" to private asylums, it must be remembered what a very insignificant fraction 426 per annum represents among the many thousands (20,000, if I mistake not) of mental cases which came within the cognizance of the Lunacy Commission in 1913.

Dr. Steen thinks I have spoken slightingly of the qualifications of mental nurses; but I did not class all mental nurses as ignorant and incompetent. What I alluded to was the uncomprehending treatment so often administered by many of them. In many asylums the staff nurses could not be excelled in kindly interest, intuition, tact, and patience, even though the majority have had no hospital training.

As to nerve-shaken soldiers, Dr. Goodall has entirely misunderstood what I referred to. I was not speaking of asylums which have been completely commandeered for the sole accommodation of the sick and wounded, and have thus entirely changed their character. I referred to the placing of soldiers whom the War Office acknowledges to be "uncertifiable" in a block of the Middlesex County Asylum at Wandsworth, the remainder of whose inmates are lunatics. This would be illegal if the soldier were a civilian. The public, knowing him to be slightly unbalanced, and finding him in such a place, cannot discriminate as to whether he has been certified as a lunatic or not. This very case was ably put forward in a leading article in The LANCET on Jan. 23rd, 1915. It is not a question of how well the soldiers are treated there; however excellent the treatment, the taint remains. Lord Knutsford obtained the sanction of the Army Council for hospital treatment for officers to shield them from being associated with asylum taint, but the men run as great a risk, and may find it difficult to obtain employment when the war is over. The War Office has given repeated assurances that the soldiers should not be placed under lunacy control. The report of the Murray Committee on Disablement points out also how prejudicial to a man's industrial future such a course may be. There is therefore the greater reason for taking this into consideration where the soldier has not been diagnosed as mentally affected, but only as transiently unstrung.

I am, Sir, yours faithfully,

August 7th, 1915. S. E. Whiте, M.B., B.Sc. Lond.

\section{EVOLUTIONARY ETIOLOGICAL FACTORS IN DISEASE.}

To the Editor of THE LANCET.

SIR,-In The Lancet of July 31st Dr. J. T. C. Nash deals with specificity from a standpoint that seems to me to require clarification. One would like to know exactly what Dr. Nash wishes to convey when, having referred to relative specificity as an attribute of the infectious diseases, he writes of an etiological link between them in a way that appears to be intentionally indefinite. While realising that a tentative proposition requires careful handling, one is curious to learn whether Dr. Nash's views amount to an attack on the thesis that certain infectious diseases are individual in origin. The term "individual" here predicates that each of the diseases has as its essential cause a germ which, despite variation and the possible coöperation of extrinsic factors, never becomes the essential cause of any of the others.

I am, Sir, yours faithfully,

Wimpole-street, W., August 5th, $1915 . \quad$ JOHN BIERN.ACKI.
FATALITIES WITH HEDONAL.

To the Editor of THE LANCET.

SIR,-Will you tell me the quickest way to find out information regarding all deaths from hedonal used as an anæsthetic ?-I am, Sir, yours faithfully, July 29th, 1915. EUREKA.

*** Although complete English statistics are wanting respecting the behaviour of hedonal as an anæsthetic, the Registrar-General now obtains from coroners, as well as from medical practitioners, particulars of all deaths resulting from the administration of anæsthetics ; and since 1911 special tables have appeared in his annual reports giving full details of such deaths and of the particular anæsthetic employed in each case. From the fact that since the Census year only three deaths have been attributed to hedonal in the whole of England and Wales, a high margin of safety might be attributed to its use; but the limitations suggested in an annotation on p. 346 shonld be observed. Past experience of the use of hedonal as a general anæsthetic appears to have been over favourable, and many medical men would like the further information on the subject which "Eureka" asks for.-ED. L.

\section{THE INFLUENCE OF LACTATION ON AN OVARIAN GRAFT. \\ To the Editor of THE LANCET.}

Sir,-Many examples of more or less successful graftings of ovaries into the abdominal wall or peritoneal cavity of the human female have been recorded at different times. Among others, the late Mr. Scott Carmichael published successful cases, but as such ovaries have been unavoidably removed on account of pathological conditions of the adjacent viscera, the influence of lactation on such grafts had not been proved. It might almost have been said that it was never likely to be demonstrated, since the usual condition that involves removal of ovaries that are fit for grafting (in part or as a whole) is inflammatory disease of the Fallopian tubes or a tumour of the uterus. Under such circumstances absolute sterility is bound to ensue, and the use of the ovarian graft is to delay the onset of the operative menopause.

In the Medical Journal of Australia for January an extraordinary, and it is to be hoped unique, case is recorded and has just come under my eye. It is a case in which normal healthy ovaries were excised during a Cæsarean section as a means of sterilising the patient. The ovaries were subsequently grafted into the abdominal wall. Why such an unusual procedure should have replaced the ordinary operation of removal of the tubes and invagination of the stumps is not explained, and no supposed advantages are mentioned that could in any way outweigh the obvious disadvantages of so gross a castration. We are simply told that the operator decided, "owing to the tuber. cular condition of the patient and her physical deformities, to sterilise her by transplanting her ovaries." Fortunately this rash proceeding was, at any rate, temporarily successful, as the result of grafting (into the abdominal muscles) was that the onset of the menopause was prevented and the patient menstruated at intervals when last seen three and a half years after the operation. Although it was recognised that lactation exerts a "profound influence ...... on the physiology of the reproductive organs of the female," and although she had signs of advanced tuberculous disease with a discharging sinus in the right hip, she was actually allowed to suckle the child for five months. It is of considerable interest to note that in spite of the possible influence of the lactation on the grafts the patient commenced to menstruate about a month after she 